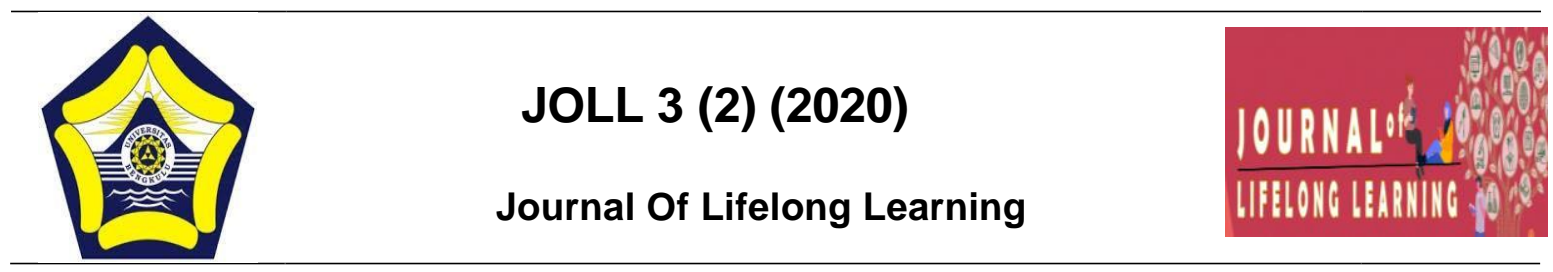

\title{
METODE PELATIHAN BUDIDAYA JAMUR TIRAM PUTIH DI YAYASAN AKADEMI PERADABAN DESA DANGAU DATUK KECAMATAN SELEBAR KOTA BENGKULU
}

\author{
Harvela Liana1,Agus Zainal Rachmat ${ }^{2}$, Suardi Jasma ${ }^{3}$ \\ ${ }^{1}$ Harvela Liana, Universitas Bengkulu, Indonesia, Hervela20@gamil.com \\ ${ }^{2}$ Agus Zainal Rachamat, Universitas Bengkulu, Indonesia, aguszainal@ unib.ac.id \\ ${ }^{3}$ Suardi Jasma, Universitas Bengkulu, Indonesia, suardijasma@unib.ac.id
}

\begin{abstract}
This research is a descriptive qualitative research which aims to describe the training method for cultivating white oyster mushrooms at the Akademi Per Civilization Foundation, Dangau Datuk Village, District as wide as Bengkulu City which is held in Bukit Makmur Village, North Bengkulu Regency. The research subjects in this study were the Director of the Dangau Village Civilization Academy Foundation, Datuk Village, training instructors, and training participants in white oyster mushroom cultivation. This research was conducted at the Dangau Datuk Village Civilization Academy Foundation and Bukit Makmur Village, North Bengkulu on 16 s.d. March 23, 2020. The data collection techniques used interview, observation and documentation techniques. Data analysis techniques include data reduction, data presentation, and drawing conclusions. Checking the validity of the data using triangulation techniques. The results showed that the white oyster mushroom cultivation training methods used by the training instructors for white oyster mushroom cultivation were lecture, question and answer, and demonstration methods. Training on white oyster mushroom cultivation at the Dangau Datuk Village Civilization Academy Foundation was held in a prosperous hill village with more emphasis on demonstration methods. With the demonstrator method, the process of accepting training participants given by the instructor will be more memorable.
\end{abstract}

Keywords: Training, Cultivation, White Oyster Mushroom

C2020 DeptofNonformalEducationUNIB ISSN : 2715-9809

\section{Addresscorrespondence:}

Jl.W.R.Supratman,KandangLimun,MuaraBangkaHulu,

KotaBengkulu,Bengkulu38371 


\section{PENDAHULUAN}

Sumber daya manusia (SDM) tidak lepas dari kegiatan pelatihan supaya memiliki keahlian dan berkembang. Martis dan Jakson dalam Nurul Quroin dan Tri Wulida.A (2018:196) "pelatihan merupakan proses seorang karyawan agar memperoleh dan meningkatkan kemampuan baru untuk melakukan suatu pekerjaan".

Moekijat (1981) dalam Kamil (2010:11) mengatakan bahwa tujuan umum pelatihan adalah mengembangkan keahlian, sehingga pekerjaan dapat dilaksanakan dengan lebih cepat dan lebih efektif,mengembangkan pengetahuan, sehingga pekerjaan dapat diselesaikan secara rasional, mengembangkan sikap, sehingga menimbulkan kemauan untuk bekerjasama.

Menurut kamus besar bahasa indonesia (KBBI) budi daya adalah usaha yang bermanfaat dan memberi hasil. Jadi segala sesuatu yang berhubungan dengan usaha manusia supaya bermanfaat dan memberikan hasil adalah bentuk dari kegiatan budidaya.

Pendidikan non formal berupa pelatihan sangat penting untuk meningkatkan keterampilan dan keahlian kerja seseorang demi menunjang taraf hidup masyarakat. Di Provinsi Bengkulu sendiri, terdapat salah satu lembaga yang bergerak di bidang pemberdayaan masyarakat dan menyelenggarakan pendidikan non formal berupa pelatihan yaitu "Yayasan Akademi Peradaban Desa Dangau Datuk".

Yayasan Akademi Peradaban Dangau Datuk berdiri pada tanggal 16 Oktober 2018. Yayasan Akademi Peradaban Desa Dangau Datuk berkedudukan dan berkantor pusat di Jalan Raya Air Sebakul,
Kelurahan Betungan, Kecamatan Selebar, Kota Bengkulu, Provinsi Bengkulu dan di inisiasi oleh Dr. Ir. Hermen Malik, M.Sc dan aktivis-aktivis sosial yang berkiprah langsung dikomunitas Dangau Datuk. Sampai saat ini pelatihan yang ada antara lain pelatihan kewirausahaan, pelatihan pengolahan kopi, pelatihan sablon, pelatihan pengolahan bumdes, pelatihan menjahit, pelatihan keterampilan kerajinan tangan, serta pelatihan budidaya jamur tiram putih.

Pelatihan terhitung sampai bulan Desember 2019, Yayasan Akademi Peradaban Desa Dangau Datuk telah melakukan pelatihan di 12 desa dalam 7 (tujuh) kabupaten di Propinsi Bengkulu, yaitu Desa Bukit Makmur, Desa Tanjung Anom (Bengkulu Utara), Desa Sukau kayo, Desa Talang Kerinci (Lebong), Desa Agung Jaya, Desa Rawa Bangun, dan Desa Sido Dadi (Muko-Muko). Desa Sidodadi (Bengkulu Tengah) Desa Sosokan Baru(Kepahiang). Desa Air Lanang (rejang Lebong). Desa Tanjung Eran (Bengkulu Selatan). Desa Ulu Danau ( Bengkulu Tengah). Pelatihan juga dilaksanakan di yayasan akademi peradaban desa dangau datuk kota bengkulu. dengan jumlah peserta pelatihan 30-50 orang setiap pelatihan. Peserta pelatihan yang mengikuti pelatihan diantaranya ibu-ibu rumah tangga, bapakbapak, dan remaja desa.

bahan-bahan yang digunakan untuk membuat 150 baglog media tumbuh jamur tiram antara lain serbuk kayu gergaji 100 $\mathrm{Kg}$, dedak 10-12 Kg, kapur pertanian 1,5 $\mathrm{Kg}$, air 30 (tiga puluh) liter, bibit 4 (empat) botol, plastik besar ukuran $35 \times 18 \times 064$ (empat) pak, plastik kecil 10x5x03 4 (empat) pak, dan cincin jamur 150 biji. 
Abang eko mengatakan alat-alat yang digunakan untuk budidaya jamur tiram antara lain drum, cangkul, sekop, dan timbangan.

Direktur yayasan memberi keterangan bahwasanya pelatihan budidaya jamur tiram putih untuk masyarakat di Provinsi Bengkulu bertujuan untuk meningkatkan perekonomian dan gizi masyarakat.

Jamur dikenal sebagai bahan makanan pelengkap yang dikonsumsi masyarakat, karena memiliki nilai gizi tinggi. Sebagian besar jamur yang dibudidayakan merupakan jamur pangan, namun ada juga jamur yang berkhasiat untuk obat. Wahyuni dalam Anonimous (2009), menyatakan bahwa kandungan senyawa kimia jamur tiram putih secara klinis berkhasiat mengobati berbagai penyakit seperti tekanan darah tinggi, diabetes, kelebihan kolesterol, anemia, meningkatkan daya tahan tubuh terhadap serangan polio dan influenza serta kekurangan gizi.

Berdasarkan paparan di atas tentang pelatihan budidaya jamur tiram putih, maka peneliti tertarik untuk melihat dan meneliti lebih lanjut tentang "Metode Pelatihan Budidaya Jamur Tiram Putih di Yayasan Akademi Peradaban Desa Dangau Datuk.”

\section{METODE}

Jenis metode penelitian yang digunakan adalah kualitatif deskriptif, teknik pengumpulan data yang digunakan adalah wawancara, observasi dan dokumentasi.

Wawancara digunakan sebagai teknik pengumpulan data untuk memperoleh data yang mendalam tentang metode palatihan budidaya jamur tiram putih di Yayasan Akademi Peradaban Desa Dangau Datuk Kota Bengkulu. Selanjutnya Observasi dalam penelitian kualitatif merupakan teknik dasar yang bisa dilakukan. Observasi yang peneliti gunakan adalah non partisipan (non participation).

Untuk menguji validitas data, peneliti menggunakan teknik triangulasi. Sebagaimana pendapat (Wiliam Wiersma,1986) dalam Sugiyono (2012:273274) yang menyatakan bahwa : Teknik triangulasi adalah sebagai pengecekan data dari berbagai sumber dengan berbagai cara dan berbagai waktu. Dengan demikian terdapat triangulasi sumber, triangulasi teknik pengumpulan dan dan triangulasi waktu.

\section{HASIL DAN PEMBAHASAN.}

Penelitian ini dilakukan di dua tempat, yaitu di Yayasan Akademi Peradaban Desa Dangau Datuk Kecamatan Selebar, Kota Bengkulu dan di Desa Bukit Makmur, Bengkulu Utara. Instruktur pelatihan budidaya jamur tiram putih di Yayasan Akademi Peradaban Desa Dangau Datuk menerapkan Metode pembelajaran dalam pelatihan. Adapun metode pembelajaran yang diterapkan adalah ceramah, tanya jawab, dan metode demonstrasi. Pelatihan budidaya jamur tiram putih di desa bukit makmur lebih menekankan pada metode pembelajaran demonstrasi, karena instruktur lebih mengutamakan praktek langsung dengan memperagakan barang-barang yang digunakan dalam pelatihan budidaya jamur tiram putih. Pertama instruktur pelatihan mengintruksikan peserta pelatihan untuk membentuk klompok besar, lalu instruktur 
pelatihan menyiapkan alat-alat dan bahan pembuatan media tanam jamur tiram putih. Instruktur pelatihan budidaya jamur tiram putih memperagakan alat dan bahan dalam pembuatan beglog jamur (media tanam jamur tiram) dan praktek langsung cara pembuatan media tanam jamur tiram (pengayakan serbuk gergaji, pencampuran kapur pertanian dan air ke serbuk gergaji,memasukan serbuk gergaji ke dalam kantong plastik, sterilisasi,inukulasi bibit,inkubasi, dan pemindahan ketempat budidaya).

Untuk mempermudah peneliti memperoleh data dan informasi, Penelitian ini mengunakan teknik pengumpulan data berupa wawancara, observasi dokumentasi.

Wawancra digunakan sebagai teknik pengumpulan data apabila peneliti ingin melakukan studi pendahuluan untuk menemukan permasalahan yang harus diteliti, tetapi juga apabila peneliti ingin mengetahui hal-hal dari responden yang lebih mendalam. Teknik pengumpulan data ini mendasarkan diri pada laporan tentang diri sendiri atau self-report, atau setidaktidaknya pada pengetahuan dan atau keyakinan pribadi.

Dokumentasi merupakan catatan peristiwa yang sudah berlalu. Dokumen bisa berbentuk tulisan, gambar atau karya-karya monumental dari seseorang. Dokumen yang berbentuk tulisan misalnya catatan harian, sejarah kehidupan (life histories), cerita, biografi, peraturan, kebijakan. Dokumen yang berbentuk gambar misalnya foto, gambar hidup, sketsa, dan lain-lain. Dokumen yang berbentuk karya misalnya karya seni, yang dapat berupa gambar, patung, film, dan lain-lain.
1) Metode ceramah

Berdasarkan temuan penelitian terkait dengan mendeskripsikan metode pelatihan dalam pelatihan budidaya jamur tiram putih, diperoleh hasil penelitian bahwa instruktur pelatihan budidaya jamur tiram mengunakan metode ceramah.

Langkah-langkah untuk menerapkan metode ceramah : 1. Berdoa, 2. Presensi siswa, 3. Guru memberikan penjelasan pendahuluan, 4. Guru mengambarkan sistem rem di papan tulis, 5. Guru menerangkan berasal dari gambar tersebut, 6. Guru menerangkan cara kerja, nama komponen, dan trouble shooting dari sistem rem, 7. Guru memberikan latihan soal. Dalam Beni Harsono, ddk (2009:72)

Pertama Instruktur pelatihan dalam pelatihan budidaya jamur tiram putih menerapkan metode ceramah dalam pelaksanaan pelatihan budidaya jamur tiram putih. Langkah-langkah yang dilakukan instrktur yang paling utama adalah mengumpulkan peserta pelatihan budidaya jamur tiram putih kedalam ruangan untuk memberikan materi pelatihan, lalu berdoa, setelah itu instruktur pelatihan membagikan modul pembelajaran dan absen kepada peserta secara bersamaan. Selanjutnya instruktur pelatihan menjelaskan materi pelatihan budidaya jamur tiram putih yang ada di modul pembelajaran, selain di modul pelatihan materi pelatihan dijelaskan dan di tampilkan melalui power point. Setelah semua materi pelatihan budidaya jamur tiram putih telah dijelaskan kepada peserta, instruktur pelatihan memberikan pertanyaan kepada peserta mengenai materi yang telah di sampaikan, selain itu instruktur pelatihan mempersilahkan peserta untuk bertanya 
mengenai materi pelatihan yang telah disampaikan instruktur pelatihan.

2) Metode tanya jawab

Berdasarkan temuan penelitian terkait dengan mendeskripsikan metode pelatihan dalam pelatihan budidaya jamur tiram putih, diperoleh hasil penelitian bahwa instruktur pelatihan budidaya jamur tiram mengunakan metode tanya jawab.

$$
\text { Sukriyatun Gunarti (2016:61) }
$$

Penggunaan metoda Tanya jawab, perlu dilakukan langkah-langkah sebagai berikut : 1. Masalah yang dibahas berkenaan dengan materi yang disampaikan atau dibahas saat itu dalam kelas yang mengandung pro dan kontra, 2. Peserta didik diarahkan menganalisa bagian yang menjadi "masalah" dan "isu" yang disampaikan oleh guru sebelum Tanya jawab berlangsung, 3 . Masalah dipecahkan melalui pengetahuan dan kemampuan yang dimiliki peserta didik dengan menerapkan metode ilmiah (logis), 4. Guru hanya berperan sebagai pengarah agar permasalahan tidak menyimpang, 5 . Rekomendasi pemecahan harus berpijak pada nilai-nilai yang ada.

Metode tanya jawab diterapkan instruktur pelatihan setelah pemberian materi pelatihan budidaya jamur tiram putih. Pertama instruktur pelatihan budidaya jamur tiram putih menanyakan mengenai materi pokok yang telah dijelaskan di dalam modul dan power point, peserta pelatihan wajib menjawab pertanyaan dari instruktur pelatihan, selain itu peserta pelatihan dipersilakan untuk bertanya kembali mengenai materi yang telah disampaikan kepada instruktur pelatihan.. metode ini bertujuan untuk mengetahui tingkat pengetahuan dan perkembangan peserta pelatihan.

3) Metode demonstrasi

Berdasarkan temuan penelitian terkait dengan mendeskripsikan metode pelatihan dalam pelatihan budidaya jamur tiram putih, diperoleh hasil penelitian bahwa instruktur pelatihan budidaya jamur tiram mengunakan metode demonstrasi..

Langkah-langkah menerapkan metode demonstrasi seperti yang diusulkan oleh Andayani dan Suyanto dalam Rifai (2017:175) adalah sebagai berikut 1. Guru menyampaikan kompetensi yang di capai (Tujuan pembelajaran khusus), 2. Guru menyajikan gambaran sekilas materi yang akan disajikan, 3. Menyiapkan bahan/alat yang diperlukan. Menunjuk salah seorang atau beberapa siswa untuk mendemonstrasikan semua skenario yang telah disiapkan, 4. Seluruh siswa memperhatikan demonstrasi dan menganalisanya, 5. Setiap siswa mengemukakan hasil analisanya dan juga pengalaman siswa didemonstrasikan, 6 . Guru dan siswa membuat kesimpulan.

Metode demonstrasi dditerapkan instruktur pelatihan setelah materi diberikan, metode ini bertujuan agar peserta pelatihan dapat memahami dan membuat media tanam jamur tiram putih. Instruktur pelatihan mengintruksikan peserta pelatihan supaya membentuk klompok besar, lalu instruktur pelatihan menyiapkan alat-alat dan bahan pembuatan media tanam jamur tiram putih. Instruktur pelatihan budidaya jamur tiram putih memperagakan alat dan bahan dalam pembuatan beglog jamur (media tanam jamur tiram) dan praktek langsung cara pembuatan media tanam jamur tiram 
(pengayakan serbuk gergaji, pencampuran kapur pertanian dan air ke serbuk gergaji,memasukan serbuk gergaji ke dalam kantong plastik, sterilisasi,inukulasi bibit,inkubasi, dan pemindahan ketempat budidaya). Setelah itu peserta pelatihan diinturksikan membentuk kelompok untuk memperagakan alat dan bahan yang telah disediakan instruktur palatihan untuk membuat media tanam jamur tiram putih. Pada tahap akhir peserta menjelaskan tentang hal yang telah ia peragakan kepada peserta pelatihan yang lain.

\section{KESIMPULAN}

Berdasarkan temuan penelitian terkait dengan mendeskripsikan metode pembelajaran dalam pelatihan budidaya jamur tiram putih disimpulkan bahwa metode pembelajran pada pelatihan budidaya jamur tiram putih di desa Bukit Makmur, Bengkulu Utara menggunakan metode ceramah, tanya jawab, dan metode demonstrasi. Pelatihan budidaya jamur tiram putih di desa bukit makmur lebih menekankan pada metode pembelajaran demonstrasi, karena instruktur lebih mengutamakan praktek langsung dengan memperagakan barang-barang yang digunakan dalam pelatihan budidaya jamur tiram putih. Instruktur pelatihan budidaya jamur tiram putih memperagakan alat-alat dalam pembuatan beglog jamur (media tanam jamur tiram) dan praktek langsung cara pembuatan media tanam jamur tiram (pengayakan serbuk gergaji, pencampuran kapur pertanian dan air ke serbuk gergaji, memasukan serbuk gergaji ke dalam kantong plastik, sterilisasi, inukulasi bibit, inkubasi, dan pemindahan ketempat budidaya). Dengan metode demonstran, proses penerimaan peserta terhadap pelatihan yang diberikan instruktur akan lebih berkesan secara mendalam. Peserta pelatihan budidaya jamur tiram putih dapat mengamati instruktur pelatihan selama proses pelatihan berlangsung. Penggunaan metode demonstrasi mempunyai tujuan agar peserta pelatihan budidaya jamur tiram putih di desa Bukit, Makmur Bengkulu Utara memahami tentang cara budidaya jamur tiram putih, dari proses awal sampai akhir pembuatan media tanam jamur tram putih. Metode yang digunakan dalam pelatihan budidaya jamur tiram di desa Bukit Makmur efektif, karena peserta pelatihan bisa membuat media tanam jamur tiram tanpa dibantu oleh instruktur pelatihan.

\section{REFERENSI}

Fuad, Anis \& Sapto Kandung N. (2013). Panduan Praktis Penelitian Kualitatif. Yogyakarta : Graha Ilmu. Harsono, Beni. Perbedaan hasil Belajar Antara Metode Ceramah Konvensional Dengan Ceramah Berbantuan Media Animasi Pada Pembelajaran Kompetensi Perakitan dan Pemasangan Rem. Vol 9 No 2

Kamil, Mustofa. 2010. Model Pendidikan dan Pelatihan (Konsep dan Aplikasi). Bandung: Alfabeth.

Qhurotin, Nurul., Tri Wulida. A. Analisis Pelatihan dan Pengembangan Sumber Daya Manusia di PT Beon Intermedia Cabang Malang. Vol 64 No 1

Rifai. Penerapan Metode Demonstrasi Untuk Meningkatkan Hasil Belajar Pendidikan Agama Kristen Materi 
Pembelajaran Sakramen Penjamuan Kudus VIII SMP Negeri 17 Surakarta. Vol 1 No 2

Sugiyono. 2012. Metode Penelitian Kuantitatif Kualitatif dan $R \& D$. Bandung : Alfabet

Sukriyatun, Gunarti. Penerapan Metode

Tanya Jawab Untuk Meningkatkan Pemahaman Peserta Didik Pada Mata Pelajaran IPS (Sejarah) 9.1 Tentang Perang Dunia II, di SMPN 16 Kota Bogor Tahun Pelajaran 2012/2013. Vol 11 No 2 